\title{
História, ciência e saúde coletiva
}

\author{
History, Science, and Collective Health
}

Gilberto Hochman (https://orcid.org/0000-0001-7834-336X) ${ }^{1}$

\footnotetext{
${ }^{1}$ Casa de Oswaldo Cruz, Fiocruz. Av. Brasil 4365, Manguinhos. 21040-900 Rio de Janeiro RJ Brasil. gilberto.hochman@fiocruz.br

\begin{abstract}
The article analyzes the presence of the history of health in the "Journal Ciência \& Saúde Coletiva" from 1996 to 2020, exploring relations between the disciplinary field of history and the multidisciplinary field of public health and examining their tensions, commonalities, and potential synergies. It shows how the history of health has featured in the journal's articles and issues over the course of the journal's twenty-five years and describes the main initiatives, results, and topics addressed in this realm. The article then offers a critical evaluation and discusses pathways for boosting the presence of history in articles and thematic issues of "Journal Ciência \& Saúde Coletiva".

Key words History, Public health, Scientific periodicals, Human sciences, Health policies
\end{abstract}

Resumo $O$ artigo analisa a presença da história da saúde no periódico "Revista Ciência \& Saúde Coletiva" entre 1996 e 2020. Discute as relações entre o campo disciplinar da história e a multidisciplinaridade da saúde coletiva, suas tensões, convergências e potenciais sinergias. Apresenta a trajetória do tema da história da saúde nos artigos e fascículos ao longo dos 25 anos de existência da revista, as principais iniciativas, resultados e temáticas abordadas. Faz um balanço crítico e discute caminhos para incrementar presença da história em artigos e números temáticos de "Revista Ciência \& Saúde Coletiva”.

Palavras-chave História, Saúde pública, Periódicos científicos, Ciências humanas, Políticas de saúde 


\section{Introdução}

A história é parte do campo da saúde coletiva no Brasil desde a conformação deste no último quarto do século XX, compondo o movimento das ciências humanas e sociais em saúde. A partir do início deste século, os historiadores têm se apresentado com uma identidade disciplinar mais distintiva fruto de inúmeros processos de institucionalização, tanto da história, bem mais longevo, como da saúde coletiva, mais recente. Essa associação tem sido positiva do ponto de vista intelectual e político, mas seus caminhos merecem ser escrutinados. O modo pelo qual a saúde coletiva interagiu e incorporou a história tem sido bastante diverso e sua dinâmica pode ser em parte apreendida no conjunto dos artigos publicados em Revista Ciência \& Saúde Coletiva desde 1996.

Como arena multidisciplinar, a saúde coletiva demanda a compreensão sobre espaço/tempo de seus processos e também aciona a história para conferir legitimidade ao presente, celebrar conquistas, reforçar identidades profissionais, relembrar eventos e perscrutar marcos do passado com $o$ intento de dar sentido às narrativas do presente e proposições de futuro ${ }^{1}$.E, muitas vezes, busca as "lições da história", principalmente em momentos de crise política e sanitária como nos eventos epidêmicos. A reconstrução intelectual e política das filiações e origens progressistas da reforma sanitária e do Sistema Único de Saúde foi um dos esforços mais prolíficos na direção da história da saúde coletiva. A história seria, para muitos, tanto a reconstrução de uma linhagem política e intelectual como um território de aprendizagem que poderia informar escolhas e ações no campo da saúde pública².

Trazer o passado de volta ao presente como elemento da análise das políticas e ações de saúde, para além de seu papel na formação profissional, tem sido uma reivindicação daqueles que compreendem que "política pública é sempre história" ${ }^{3}$ e, por conseguinte, saúde pública seria história. Para o historiador norte-americano Charles Rosenberg, a maior contribuição da história para as políticas de saúde seria o seu fundamental sentido de contingência e complexidade da experiência individual e social com a saúde e a doença. De modo reflexivo, ressalta que a interação com a saúde coletiva impediria que historiadores produzam contextos despolitizados ${ }^{3}$. A história seria simultaneamente conhecimento e ação política.

A resposta de parte dos historiadores profissionais a essa demanda tem sido, portanto, posi- tiva em uma direção semelhante, mas com objetivo inverso, isto é, o de transformar o presente em histórico. O esforço de parte da disciplina tem sido se aproximar das questões contemporâneas nas quais o historiador é testemunha e analista, a partir de seus recursos metodológicos específicos. Desse modo, a história estaria também autorizada a falar sobre o presente, desenhando-se um quadro que, potencialmente, pode gerar mais a competição do que o diálogo.

Contudo esses "usos da história" não são temas pacificados. Este campo disciplinar tende a recusar a ideia de aprendizado, ou de uma "história mestra da vida" ou a história como escola do presente, mesmo quando se reconhece a intricada relação do presente com o passado. O historiador inglês Quentin Skinner ao escrever sobre o "lugar da história na vida pública" ressalta que, mesmo reconhecendo que a história pode servir a propósitos públicos, espera que os historiadores não transformem essa aspiração em seu objetivo principal ${ }^{4}$. Como frisa Rosenberg, os historiadores sentem-se desconfortáveis com prognósticos que são, justamente, uma das maiores expectativas dos formuladores de políticas ${ }^{3}$. Contudo, alertados pelo debate teórico sobre o presentismo, sobre a especificidade dos contextos e do passado e sobre o perigo das analogias históricas e as distorções que uma certa "história pública" pode produzir, um conjunto crescente de historiadores reafirmam que a história importa tanto como disciplina acadêmica quanto como para o debate público e para os formuladores, decisores e implementadores de políticas ${ }^{5}$. Essa é uma tensão relevante para se compreender as relações da história como campo disciplinar e profissional e a saúde coletiva, geneticamente multiprofissional e pluridisciplinar.

Todavia, foram nessas inquietudes e expectativas que se conformou a perspectiva histórica dos fenômenos da saúde e da doença que está consolidada como um campo - história da saúde - no Brasil. Este campo não é monopolístico e esta perspectiva está presente em diferentes áreas, associações, instituições e periódicos científicos. Ele se beneficia por não importar o debate europeu e estadunidense sobre definições de história da medicina, história médica, história da saúde, história da saúde pública e história das doenças, sobre suas nebulosas fronteiras ou mesmo em suas variações como história social ${ }^{6}$. A elasticidade conceitual e política desse campo permite compreendê-lo, na sua gênese e consolidação, a partir de inúmeras facetas e, por sua vez, a natureza da saúde coletiva convida a esse diálogo. 
A saúde coletiva foi construída por uma multiplicidade de indivíduos, grupos e instituições em várias áreas do conhecimento e de prática profissional, situados no Brasil e também no exterior. Esse foi um processo historicamente polifônico e polissêmico que, por isso mesmo, constrange monopólios - sejam eles interpretativos, metodológicos, institucionais ou políticos. Do ponto de vista da compreensão dos seus processos constitutivos esse diálogo com a história ajudou a matizar duas vertentes sobre o lugar e o papel dos médicos e profissionais de saúde muito presentes nos trabalhos inaugurais da saúde coletiva em perspectiva histórica entre o fim da década de 1970 e meados dos anos 1980: uma visão mais heroica e reformista da medicina social decalcada da obra de George Rosen e Henry Sigerist e uma concepção mais crítica da medicina social e das tramas do biopoder extraída dos trabalhos de Michel Foucault ${ }^{7}$.

O lugar da história na saúde coletiva e na $R e$ vista Ciência \& Saúde Coletiva foi construído ao longo de mais de duas décadas durante as quais esse campo se institucionalizou também como parte das chamadas ciências sociais e humanas em saúde. São trabalhos marcados pela democratização do Brasil e intimamente associados aos estudos sobre a reforma sanitária em seus primeiros anos e, depois, nos seus impasses, sobre o lugar das humanidades na saúde coletiva brasileira e na formação dos profissionais de saúde. Indicadores desse processo de institucionalização estão nas crescentes revisões bibliográficas que vêm sendo publicadas desde a década de 1990, em particular sobre história da saúde pública/ coletiva e sobre o lugar da história e das ciências sociais na saúde ${ }^{8-11}$. Esses balanços foram menos frequentes para o campo profissional da história à exceção de trabalhos que discutem a produção no campo da história institucional das ciências que tem interseções com a saúde pública, suas instituições e profissões ${ }^{12}$. Por outro caminho, têm emergido análises sobre o que já se poderia denominar de uma interpretação historiográfica da reforma sanitária brasileira ${ }^{13,14}$. A produção brasileira mais recente tem sido referenciada em artigos e livros que fazem revisões da literatura relativa aos temas da história da saúde, da doença e da medicina na América Latina e no Caribe ${ }^{15-20}$. Essa produção acadêmica tem se expressado em parte nas páginas da Revista Ciência \& Saúde Coletiva.

\section{A história da História na Revista Ciência \& Saúde Coletiva}

A presença de uma perspectiva histórica em artigos da Revista Ciência \& Saúde Coletiva entre 1996 e 2020 representa 2\% do total, isto é, 104 artigos em um universo de 5.033. Estes artigos foram selecionados primeiro, a partir de busca por diferentes termos e descritores (título, resumo, palavras-chave, texto completo) e, segundo, a leitura dos artigos resultantes dessa busca para confirmar a pertinência ou descartar os não apropriados. Há interseções significativas com outros campos disciplinares, como as ciências sociais, a educação, a nutrição, a enfermagem, a psiquiatria e a filosofia e perspectivas metodológicas como histórias de vida e história oral, análise de políticas públicas e análise comparada. A leitura permitiu definir com mais precisão uma centena de artigos que têm claramente uma perspectiva histórica.

A contribuição da história da saúde coletiva à revista foi sendo construída ao longo dos 25 anos. Esses artigos foram escritos por historiadores, mas também por cientistas sociais, médicos, biólogos, sanitaristas e profissionais de saúde que incorporam a sensibilidade histórica. A maior parte dele, cerca de $60 \%$, concentra-se em números temáticos e seções especiais e mais de $95 \%$ foi publicada a partir do ano 2000. Até esse ano, apenas 4 artigos tinham sido publicados com uma adesão à perspectiva histórica. $\mathrm{O}$ aumento do número de fascículos anuais da revista (trimestral em 2002, bimestral em 2007 e mensal a partir de 2011) possibilitou também mais espaço editorial para artigos e números temáticos em diversas áreas, inclusive para a história da saúde coletiva.

Em 2000, por ocasião das comemorações sobre 500 anos da descoberta, ou invasão, do Brasil, ou de encontro de civilizações, a Revista Ciência \& Saúde Coletiva publicou seu primeiro número com tema histórico organizado por Everardo Duarte Nunes como editor convidado. Também marcava a primeira década de um Sistema Único de Saúde (SUS) ainda em construção e um século de saúde pública no Brasil. Nunes foi, certamente, o autor que mais publicou artigos em perspectiva histórica nos primeiros anos da revista. Sob o título de 100 anos de saúde coletiva (volume 5, $\mathrm{n}^{\circ}$ 2) a revista abriu-se mais claramente para a perspectiva histórica em geral e para historiadores em particular. Em seu editorial, Nunes apresentava a senha para um diálogo interdisciplinar necessário da saúde coletiva no e do século XXI: 
... a saúde será, neste século objeto de infindáveis, mas necessárias, discussões. Não é tarefa fácil abordar a complexa rede de relações na compreensão do problema saúde, nos aspectos que nos interessam: o social, o coletivo e o público. Nesse sentido, é imprescindivel a perspectiva interdisciplinar quando se cruzam conhecimentos históricos, sociológicos, antropológicos, políticos, biológicos, demográficos, estatísticos, ecológicos. E, para isso, somente a participação de um grupo de especialistas é que torna possivel recuperar, mesmo que de forma incompleta, aquilo que vem constituindo a construção da saúde pública brasileira ${ }^{21}$.

$\mathrm{Na}$ esteira do crescimento e institucionalização do campo da história da saúde no Brasil cresceu a demanda pela perspectiva histórica na saúde coletiva e na revista ${ }^{18}$. Em 2008 foi publicado o número temático $A$ história dos trabalhadores da saúde. Esse número temático (volume $13, \mathrm{n}^{\circ} 2$ ) aprofundou a presença da perspectiva histórica em Revista Ciência \& Saúde Coletiva promovendo o diálogo entre história, profissões e trabalhadores da saúde estimulada pelo Relatório Mundial da Saúde de 2006: "Trabalhando juntos pela Saúde"22. Uma característica importante nesse número foi o aprofundamento das contribuições sobre outras experiências nacionais, como dos EUA, México, Argentina e Índia, em inglês e espanhol, denotando uma característica desse campo que é a sua intrínseca internacionalização. $\mathrm{Na}$ apresentação os editores convidados atualizaram a agenda da história da saúde coletiva na revista:

A história como instrumento de conhecimento e reflexão crítica tem estado presente no campo da saúde pública desde os seus primórdios. A agenda internacional hoje reforça esta presença, expressa pela reivindicação manifestada por historiadores, outros especialistas e gestores, de um encontro ativo da história com a saúde, visando à compreensão presente e futura das reformas dos sistemas de saúde. Ao analisar processos no tempo e no espaço, contextualizando-os e inserindo saúde e doença na sociedade e na cultura, historiadores podem informar sobre práticas passadas, iluminar opções, possibilitar comparações ${ }^{23}$.

Em 2011 foi publicado um novo volume temático articulando desta vez saúde global e história por ocasião dos 30 anos da erradicação da varíola em campanha coordenada pela Organização Mundial da Saúde (OMS) e anunciada em maio de 1980. Sob o título de Imunização, vacinas: passado e futuro (vol. 16, no 2 ) foram reunidos artigos sobre diferentes experiências históricas de vacinação e imunização desde o século XIX com ênfase na experiência da erradicação no pós-Segunda Guerra Mundial O resultado da chamada de artigos incorporou autores de diferentes instituições em diversos países com textos em inglês, espanhol e português. Este número ajudou a aprofundar a dimensão internacional da história da saúde na revista e da própria $R e-$ vista Ciência \& Saúde Coletiva. Outro aspecto a ser ressaltado é o caráter crítico da perspectiva histórica no campo da saúde. Ela deve ser "herética e incômoda" mesmo quando celebra uma conquista da saúde global conforme a carta dos editores convidados:

A análise histórica produz conhecimento e reflexão crítica ao abrir as caixas-pretas dos sucessos da saúde pública nacional e global, ao desvelar as tramas sociais e culturais envolvidas na imunização, ao investigar as redes de interesses politicos e econômicos que a envolvem e apontar a diversidade e a assimetria entre países, atores e instituições. Nesse sentido, a maior contribuição da história para a saúde pública é o seu fundamental sentido de temporalidade, espacialidade, contingência e complexidade ${ }^{24}$.

Essas iniciativas editoriais e as agendas exemplificadas nos editoriais dos números temáticos fazem parte do processo de institucionalização do campo da história da saúde no Brasil em diferentes instituições de pesquisa e ensino, sociedades científicas e associações profissionais e nos periódicos, em diversas áreas do conhecimento. Revista Ciência \& Saúde Coletiva contribuiu ativamente ao abrir espaço crescente para colaborações no campo da história. Por sua vez estas auxiliaram no adensamento do próprio campo da saúde coletiva com impacto na revista. Um indicador de reconhecimento desse processo de mão dupla foi a criação a partir de 2014 de uma editoria específica de História e Saúde, uma distinção em relação a outros periódicos no campo da saúde coletiva no Brasil e mesmo no exterior. Revistas importantes como The Lancet e o Journal of Epidemiology and Community Health publicam artigos de história de saúde mas de modo intermitente. A iniciativa da série aproxima a revista da Abrasco da American Journal of Public Health (AJPH), da argentina Salud Colectiva e da colombiana Revista de Ciencias de la Salud que têm estimulado e publicado artigos de história e historiadores, inclusive com editorias especializadas.

Por ocasião dos 20 anos de Revista Ciência \& Saúde Coletiva em 2015, criou-se a série "Construtores da Saúde Coletiva" editada por Gilberto Hochman e Everardo Nunes Duarte. Foi uma iniciativa inédita com poucos similares nacionais e internacionais como, talvez o único exemplo 
similar, a seção "Voices from the Past" da AJPH. Ao longo deste ano publicou-se 12 artigos sobre diferentes atores considerados fundamentais na arquitetura intelectual e na prática da saúde coletiva desde o pós-Segunda Guerra Mundial. Não se restringe apenas a personagens brasileiros, mas, também, a latino-americanos e europeus, cuja ideias e ações tiveram influência intelectual e institucional na saúde coletiva brasileira. Os editores convidados advertiam os leitores que nesta seção:

Não se trata de ratificar ou erigir um panteão. Ao contrário, devemos sim celebrar nossos construtores, mas situando-os criticamente em seu tempo, na história. Pretende-se também iluminar personagens que são menos visíveis, alguns efetivamente esquecidos, nas narrativas mais assentadas sobre a reforma sanitária e sobre a criação do Sistema Único de Saúde ${ }^{25}$.

A perspectiva histórica e crítica como vetor foi mais uma vez reforçada:

Os Construtores da Saúde Coletiva foram homens e mulheres que, de diferentes maneiras, pensaram, escreveram, discursaram, agiram, organizaram, administraram e, fundamentalmente, desejaram e imaginaram instituições, associações, politicas e sistemas de saúde mais públicos, nacionais, inclusivos e igualitários. Imaginação e práticas que foram eivadas de contradições, conflitos $e$ diferenças profundas sobre os caminhos a serem seguidos, em momentos e lugares diversos. As próprias terminologias que identificaram o campo são parte desse processo: higiene, saúde pública, medicina preventiva, medicina social, saúde coletiva. Foram legados e escolhas situadas no tempo e espaço $^{26}$.

A partir de 2016 se tornou uma seção da editoria de história e recebe contribuições em fluxo contínuo. Até 2020 a seção conta com 19 artigos entre publicados e aprovados. O objetivo de sua continuidade é estimular a reflexão no campo da saúde coletiva sobre a sua história a partir de uma análise crítica da trajetória de seus principais construtores e, desse modo, tornando a presença da história mais diuturna e atraente para o amplo espectro de pesquisadores e profissionais da saúde coletiva. Ao ampliar-se no tempo, a série tem publicado não apenas artigos sobre os que estão no "Panteão" da saúde coletiva e não apenas médicos, mas os esquecidos e os incômodos e, também, mulheres e negros que são sub -representados nas narrativas mais consagradas. Nessa ação pedagógica a série também amplia a concepção de história da saúde coletiva incorporando trabalhos sobre atores e processos anterio- res à institucionalização do campo que tem como marco fundamental a criação da Associação Brasileira de Saúde Coletiva (Abrasco) em 1979 o do Centro Brasileiro de Estudos de Saúde (Cebes) em 1976. E, fundamentalmente, incorpora os arquitetos e os intelectuais da saúde coletiva como “intérpretes do Brasil" agora no campo de estudos do Pensamento Social Brasileiro ${ }^{26}$.

As temáticas que frequentaram essa centena de artigos estão associadas em grande parte às chamadas para esses fascículos temáticos e seção: campanhas sanitárias, educação médica e em saúde pública, profissões, instituições e práticas de cuidado e cura, saúde global, políticas e sistemas de saúde, psiquiatria, reforma sanitária, epidemias e endemias, técnicas e tecnologias e história das doenças e das disciplinas médicas e científicas. Também aparecem artigos em perspectiva histórica em fascículos dedicados à comemoração reflexiva de marcos como a criação do SUS, a Atenção Primária em Saúde, Reforma Psiquiátrica e Reforma Sanitária. Cabe destacar o papel de Everardo Duarte Nunes ao longo dos 25 anos da revista como autor mais prolífico e incentivador da interdisciplinaridade, da história do campo da saúde coletiva e das ciências sociais em saúde.

\section{Considerações finais}

O lugar da história na Revista Ciência \& Saúde Coletiva foi se estabelecendo a partir do ano 2000. Ele conformou-se por dois movimentos. Por um lado, o crescimento do campo das ciências humanas e sociais em saúde do qual a revista é o seu principal porta-voz. Por outro, a institucionalização da área de história da saúde na saúde coletiva e também no campo da história a partir de inúmeros departamentos universitários de história e em institutos de pesquisa, grupos e linhas de pesquisa, museus, espaço em periódicos e congressos de sociedades e associações. A novidade do século XXI é o diálogo da saúde com métodos e teorias e um exaustivo compromisso com documentos e fontes que a profissionalização da história da saúde passou a requerer. Isso complexifica o desafio de um diálogo em construção dada as expectativas, por vezes divergentes como vimos, sobre os usos e o papel da história para cada campo disciplinar e profissional.

A presença ainda tímida da história da saúde na Revista Ciência \& Saúde Coletiva é derivada de fatores, alguns já indicados, que se referem tanto ao funcionamento de processos editoriais 
como das diferenças de comunidades epistêmicas e profissionais em permanente crescimento e transformação. Para um crescimento nos próximos anos é necessário compreender esses fatores e superá-los com ações editoriais. Do ponto de vista editorial mais geral, um periódico de ciências humanas e sociais em saúde compete com periódicos de história na atração de artigos em perspectiva histórica. Com a vantagem de que nestes últimos os formatos de citação, notas e bibliografia são mais amigáveis para os textos de historiadores que, na maioria das vezes, utilizam fontes primárias em vários suportes que são mais difíceis de serem referenciadas no modelo Vancouver. $\mathrm{O}$ tamanho dos artigos também constitui uma questão, pois em revistas disciplinares de histórias aceitam submissões em torno de 10-12 mil palavras, um número mais atraente para trabalhos com material empírico que caracteriza os resultados de pesquisa histórica. Por último o sistema de avaliação de periódicos na pós-graduação brasileira (Qualis), até recente exclusivamente por área de conhecimento, também diminuiu os incentivos a se publicar artigos sobre história da saúde em periódicos de saúde coletiva. $\mathrm{O}$ caráter multidisciplinar da história da saúde coletiva ainda provoca incompreensões, mencionadas anteriormente, que por vezes têm impacto nos processos avaliativos de originais submetidos à editoria de História e Saúde. Avaliadores com formações diferentes têm expectativas e exigências muitas vezes distintas em relação aos artigos submetidos demandando um papel mais ativo à editoria na consolidação das demandas por revisão e resubmissão.

O desafio de tornar mais permanente tempo e espaço como elementos constituintes dos debates, dos processos, das ideias, das práticas, das políticas, dos agentes e das agências da saúde coletiva foi superado. Porém, há, ainda, caminhos a serem trilhados para que o lugar da história da saúde se expresse de modo mais saliente em Revista Ciência \& Saúde Coletiva. Entre estes caminhos, a maior articulação entre as editorias associadas, a proposição de debates, o incentivo a números temáticos em perspectiva histórica, maior divulgação de artigos publicados e temas de história nas redes sociais e formas de comunicação pública da Abrasco e da revista.

Em tempos dramáticos e trágicos, como o da pandemia de Covid-19, o papel das ciências humanas e sociais, das quais a história faz parte, é fundamental para sua compreensão e para as respostas públicas e da sociedade à emergência sanitária. O dicionário público da pandemia é o das humanidades e da história: afastamento, contágio, crise, cuidados, desigualdade, discriminação, distopia, doença, gênero, insegurança, interação, isolamento, limpeza, máscara, medo, morte, ocultamento, políticas, práticas, remédios, resistência, resiliência, risco, ruptura, saúde, sistema, violência entre dezenas de outros vocábulos. A história em Revista Ciência \& Saúde Coletiva continuará a fazer parte desse empreendimento. 


\section{Referências}

1. Brown TM, Fee E. A role for public health history. Am J Public Health 2004; 94(11):1851-1853.

2. Silva LMV. O Campo da Saúde Coletiva - Gênese, Transformações e Articulações com a Reforma Sanitária Brasileira. Rio de Janeiro, Salvador: Editora Fiocruz, Edufba; 2018.

3. Rosenberg CE. Anticipated consequences: historians, history, and health policy. In: Stevens RA, Rosenberg $\mathrm{CE}$, Burns LR, editors. History and Health Policy in the United States. Putting the past back in. New Brunswick, London: Rutgers University Press; 2006. p. 13-31.

4. Quentin S. The place of history in public life. History $\&$ Policy, 08 november 2005 [acessado 2020 Fev 12]. Disponível em: http://www.historyandpolicy.org/policy-papers/papers/the-place-of-history-in-public-life

5. Woolcock M, Szreter S, Vijayendra R. History, Historians and Development Policy: A necessary dialogue? Manchester: Manchester University Press; 2011.

6. Huisman FG, Warner JH, editors. Locating Medical History. The Stories and their Meanings. Baltimore: John Hopkins University Press; 2004.

7. Hochman G, Pimenta TS, Teixeira LA. História da Saúde no Brasil: Uma breve história. In: Teixeira LA, Pimenta TS, Hochman G, organizadores. História da Saúde no Brasil. São Paulo: Hucitec Editora; 2018, p. 9-26.

8. Lima NT, Carvalho MAR. O argumento histórico nas análises de saúde coletiva. In: Teixeira SF, organizador. Saúde coletiva? questionando a onipotência do social. Rio de Janeiro: Relume-Dumará; 1992. p. 117-142.

9. Mota A, Schraiber LB. Medicina sob as lentes da história: reflexões teórico-metodológicas. Cien Saude Colet 2014; 19(4):1085-1094.

10. Nunes ED. Sobre a história da saúde pública: ideias e autores. Cien Saude Colet 2000; 5(2):251-264.

11. Vieira-da-Silva LM, Pinnel P. The genesis of collective health in Brazil. Sociol. Health Illn 2014; 36(3):432446.

12. Kropf SP, Hochman G. From the beginnings: debates on the history of science in Brazil. Hisp. Am. Hist. Rev 2011; 91(3):391-408.

13. Paiva CHA, Teixeira LA. Reforma sanitária e a criação do Sistema Único de Saúde: notas sobre contextos e autores. Hist. Cienc. Saude-Manguinhos 2014; 21(1):15-36.

14. Sophia DC. Saúde e Utopia - o Cebes e a Reforma Sanitária Brasileira (1976 - 1986). São Paulo: Hucitec Editora; 2015.
15. Armus D, López-Denis A. Disease, medicine and health. The Oxford Handbook of Latin American History. Oxford: Oxford University Press; 2011. p. 424-453.

16. Birn AE, Necochea R. Footprints on the future: looking forward to Latin American medical history in the Twenty-First Century. Hisp. Am. Hist. Rev 2011; 91(3):503-527.

17. Hochman G, Di Liscia MS, Palmer, S. Patologías de la patria: una introducción al tema. In: Hochman G, Di Liscia MS, Palmer S. Patologías de la patria: enfermedades, enfermos y nación en América Latina. Buenos Aires: Lugar Editorial; 2012. p. 13-27.

18. Espinosa M. Globalizing the history of disease, medicine, and public health in Latin America. Isis 2013; 104(4):798-806.

19. Cueto M, Palmer S. Medicina e saúde pública na América Latina: uma história. Rio de Janeiro: Editora Fiocruz; 2016.

20. Teixeira LA, Pimenta TS, Hochman G, organizadores. História da Saúde no Brasil. São Paulo: Hucitec Editora; 2018.

21. Nunes ED. Sobre a história da saúde pública: ideias e autores. Cien Saude Colet 2000; 5(2):251-264.

22. Organização Mundial da Saúde (OMS). Trabalhando juntos pela saúde. Brasília: Ministério da Saúde (MS); 2007.

23. Hochman G, Pires-Alves F, Lima NT. A história dos trabalhadores da saúde como política pública. Cien Saude Colet 2008; 13(3):816-816.

24. Hochman G, Bhattacharya S. Imunização, vacinas: passado e futuro. Cien Saude Colet 2011; 16(2):372372.

25. Hochman G, Nunes ED. Abertura de uma nova seção na RC\&SC. Cien Saude Colet 2015; 20(1):137-137.

26. Hochman G, Lima NT, organizadores. Médicos Intérpretes do Brasil. São Paulo: Hucitec Editora; 2015.

Artigo apresentado em 28/05/2020

Aprovado em 02/06/2020

Versão final apresentada em 04/06/2020 
